Journal of the Magnetics Society of Japan Vol. 15 Supplement, No. S2 (1991)

(C) 1991 by The Magnetics Society of Japan

\title{
MAGNETIC PROPERTIES OF CoPtB(O) ALLOY FILMS ON CONTINUOUS SUBSTRATE
}

\section{Tetsuya YAMAMOTO*, Akihiko OKABE*, Kazuhiko HAYASHI*, Masatoshi HAYAKAWA**, Kazunobu CHIBA** and Kouichi ASO*}

*Sony Corporation Research Center, 174 Fujitsuka-cho, Hodogaya-ku, Yokohama 240, Japan
**Sony Magnetic Products Inc., 3-4-1 Sakuragi, Tagajo, Miyagi 985, Japan

Abstract--.. The $\mathrm{Pt}$ and $\mathrm{Cr}$ underlayer effects of $\mathrm{CoPtB}(\mathrm{O})$ alloy films are investigated on glass substrate. Films with $\mathrm{Pt}$ underlayer showed excellent perpendicular magnetic properties and $\mathrm{Cr}$ underlayer changed the magnetic properties to have in-plane magnetization with large in-plane coercivity about 2500 Oe. These are closely related to crystallinity of CoPtB(O) layer and it is very important to have well oriented film to get excellent perpendicular magnetic properties.

On a PET substrate, it is difficult to have the perpendicular magnetization because of its bad crystallinity. A Cr underlayer also effective on the PET substrate to have in-plane coercivity over $2000 \mathrm{Oe}$.

\section{INTRODUCTION}

The $\mathrm{CoPtB}(\mathrm{O})$ alloy films have excellent hard magnetic properties with remarkably large perpendicular coercivity and high saturation magnetization. The outline of the magnetic properties and the microstructure of $\mathrm{CoPtB}(\mathrm{O})$ alloy films were already reported[1][2]. To utilize these superior characteristics as the new tape medium, it is very important to understand whether do these $\mathrm{CoPtB}(\mathrm{O})$ alloy films show their excellent characteristics on continuous substrate as realized on stationary rigid substrates or not.

In the course of studying the effects of underlayer on the magnetic properties of $\mathrm{CoPtB}(\mathrm{O})$ alloy films, it revealed that the characteristics of $\mathrm{CoPtB}(\mathrm{O})$ alloy films closely depends on their underlayer. To realize excellent perpendicular magnetic properties, the underlayer play a very important role.

In this study, $\mathrm{Pt}$ and $\mathrm{Cr}$ underlayer effects on magnetic properties and film structure were investigated using stationary glass slide substrates. Magnetic properties of the films deposited onto continuous PET substrates were investigated compared to those on the glass substrates.
Table I Typical sputtering conditions

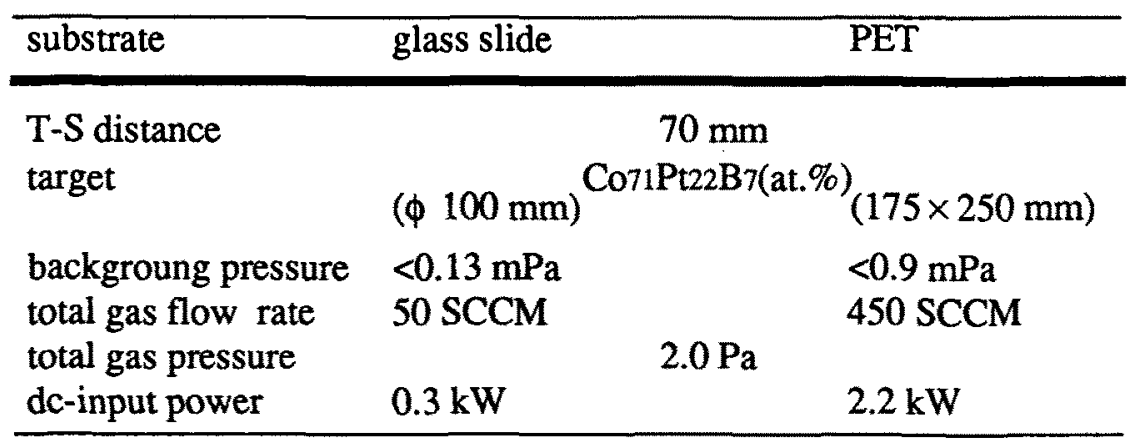




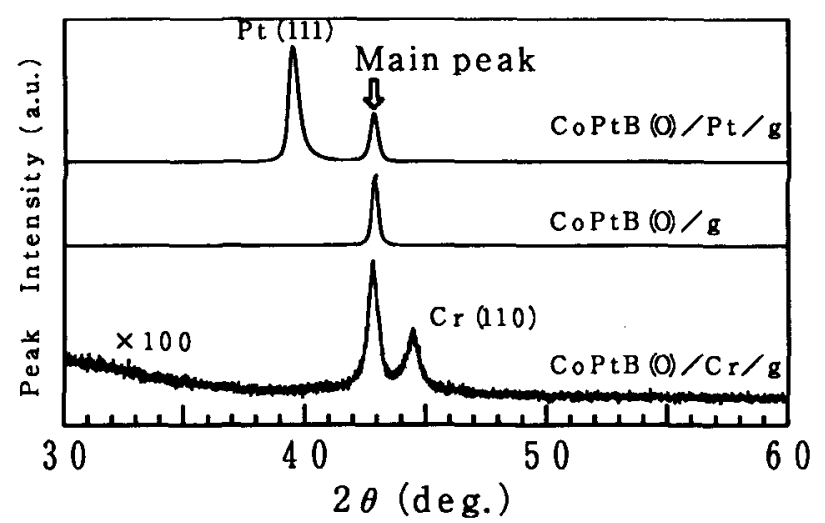

Fig.1 The X-ray diffraction patterns of $\mathrm{CoPtB}(\mathrm{O}) / \mathrm{Pt} / \mathrm{g}$ and $\mathrm{PoPtB}(\mathrm{O}) / \mathrm{g}$ and $\mathrm{CoPtB}(\mathrm{O}) / \mathrm{Cr} / \mathrm{g}$.

flexible PET substrate (thickness: $10 \mu \mathrm{m}$ ). The PET film substrate moved along a can roll. A mask and a slit located between target and substrate limited the incident angle of sputtered particles as only vertical component available and/or allowed oblique component with vertical one. Thickness of the magnetic layer of specimens was about $100 \mathrm{~nm}$.

The $\mathrm{CoPtB}(\mathrm{O})$ alloy film with $\mathrm{Pt}$ and $\mathrm{Cr}$ underlayer and without underlayer system on glass slide substrate will be written as $\mathrm{CoPtB}(\mathrm{O}) / \mathrm{Pt} / \mathrm{g}, \mathrm{CoPtB}(\mathrm{O}) / \mathrm{Cr} / \mathrm{g}$ and $\mathrm{CoPtB}(\mathrm{O}) / \mathrm{g}$ respectively, which on PET substrate will be written as $\mathrm{CoPtB}(\mathrm{O}) / \mathrm{Cr} / \mathrm{PET}$ or $\mathrm{CoPtB}(\mathrm{O}) /$ PET.

Magnetic properties were measured by using vibrating sample magnetometry with a maximum applied field of $15 \mathrm{kOe}$. Crystal structure was analyzed by using X-ray diffractometry $(\mathrm{Cu}-\mathrm{K} \alpha)$.

\section{RESULTS AND DISCUSSION}

\section{Films on stationary substrate}

Fig.1 shows the typical X-ray diffraction patterns of each types of specimens. Very strong one peak from $\operatorname{CoPtB}(O)$ layer is shown in $\mathrm{CoPtB}(\mathrm{O}) / \mathrm{Pt} / \mathrm{g}$ and $\mathrm{CoPtB}(\mathrm{O}) / \mathrm{g}$. It is difficult to decide the crystalline phase whether fcc or hep from this figure. From TEM study of $\mathrm{CoPtB}(\mathrm{O})$ alloy film with $\mathrm{Pt}$ underlayer on polyimide sheet, the crystalline phase is fcc and has orientation of [111] normal to the

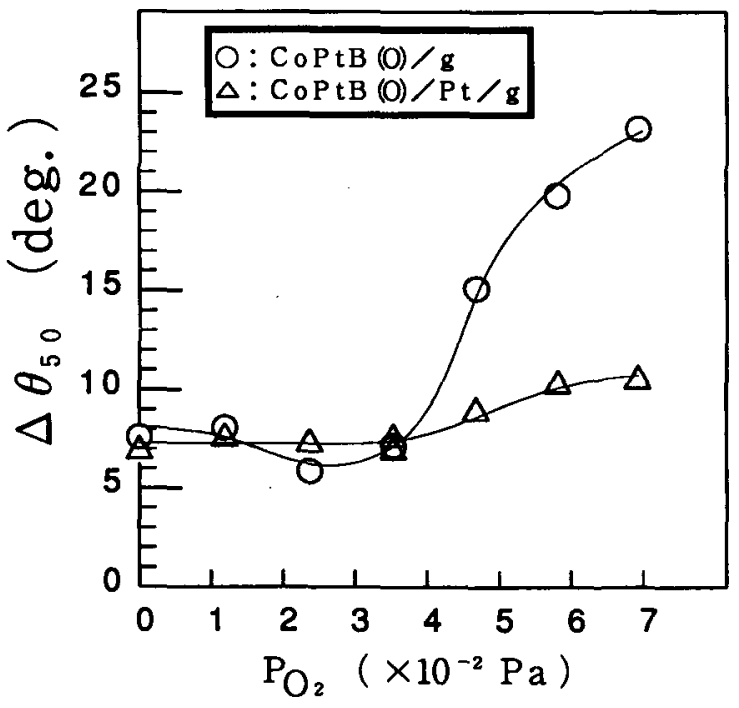

Fig.2 Dependence of $\Delta \theta 50$ on $\mathrm{PO}$.

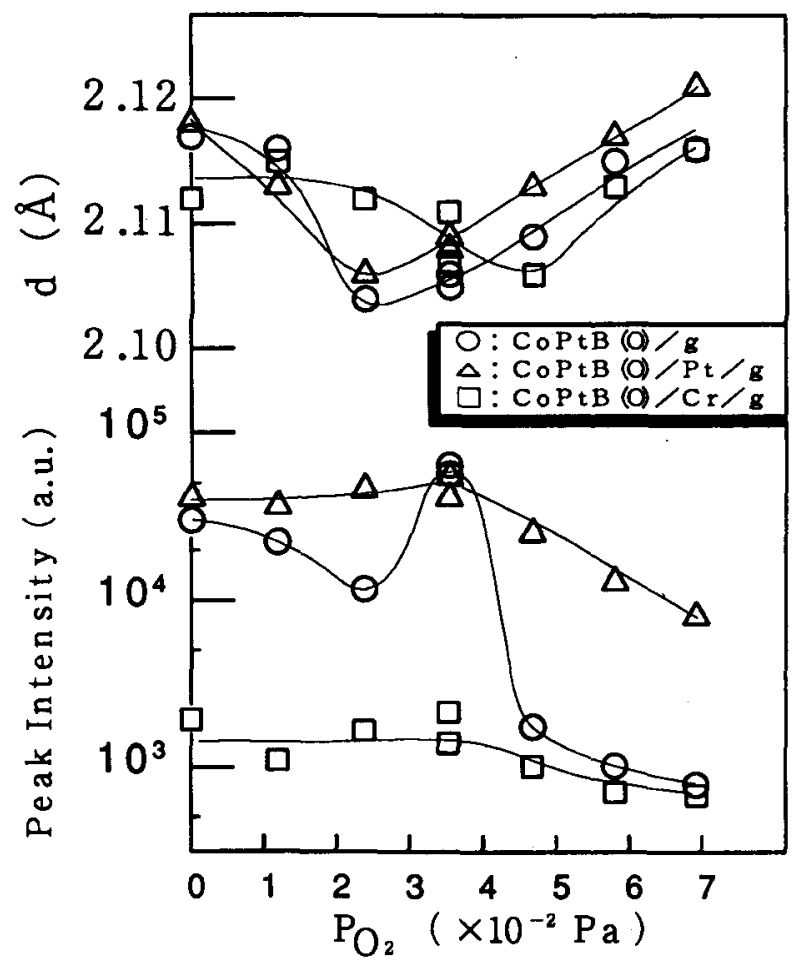

Fig.3 Dependence of $\mathrm{d}$ and X-ray peak intensity on $\mathrm{PO}$. 
plane[2]. $\Delta \theta_{50}$ was estimated from X-ray rocking curve of this fcc(111) main peak. Spacing of lattice planes $d$ and peak intensity are also derived from this main peak.

Fig.2 shows the dependence of $\Delta \theta_{50}$ of $\mathrm{CoPtB}(\mathrm{O}) / \mathrm{Pt} / \mathrm{g}$ and $\mathrm{CoPtB}(\mathrm{O}) / \mathrm{g}$ on $\mathrm{PO}$. When $\mathrm{PO}_{2}$ is below $0.035 \mathrm{~Pa}, \triangle \theta_{50}$ is nearly constant of 6 to 8 deg. in both systems. When $\mathrm{PO}_{2}$ is over $0.035 \mathrm{~Pa}, \Delta \theta_{50}$ increases rapidly to about 23 deg. in $\mathrm{CoPtB}(\mathrm{O}) / \mathrm{g}$ whereas $\Delta \theta_{50}$ of $\mathrm{CoPtB}(\mathrm{O}) /$ $\mathrm{Pt} / \mathrm{g}$ shows small increase to about $10 \mathrm{deg}$.

Fig. 3 shows the dependence of $d$ and X-ray peak intensity on PO2. The ds of these types films show same behavior of having minima with $\mathrm{PO}_{2}$ increasing. The variation of $\mathrm{d}$ in $\mathrm{CoPtB}(\mathrm{O}) / \mathrm{Cr} / \mathrm{g}$ is not so wide compared to those of $\mathrm{CoPtB}(\mathrm{O}) / \mathrm{g}$ and $\mathrm{CoPtB}(\mathrm{O}) / \mathrm{Pt} / \mathrm{g}$. The minimum point of $\mathrm{d}$ in $\mathrm{CoPtB}(\mathrm{O}) / \mathrm{Cr} / \mathrm{g}$ has the different $\mathrm{PO}_{2}$ value compared to those of the others.

The X-ray peak intensities of $\operatorname{CoPtB}(\mathrm{O}) / \mathrm{Cr} / \mathrm{g}$ are constant up to $\mathrm{PO}_{2}$ of $0.035 \mathrm{~Pa}$ and then slightly decrease with increasing $\mathrm{PO}$. Very strong peak intensity is observed in $\mathrm{CoPtB}(\mathrm{O}) /$ $\mathrm{Pt} / \mathrm{g}$ compared to that in $\mathrm{CoPtB}(\mathrm{O}) / \mathrm{Cr} / \mathrm{g}$. In $\mathrm{CoPtB}(\mathrm{O}) / \mathrm{g}$, peak intensity decreases rapidly with increasing $\mathrm{PO}_{2}$ except for $0.035 \mathrm{~Pa}$ which shows same intensity as $\mathrm{CoPtB}(\mathrm{O}) / \mathrm{Pt} / \mathrm{g}$.

Fig.4 shows the dependence of perpendicular anisotropy field $\mathrm{Hk}$ on $\mathrm{PO}_{2}$. The $\mathrm{Hk}$ was estimated from in-plane hysteresis loop. Hks of $\mathrm{CoPtB}(\mathrm{O}) / \mathrm{Pt} / \mathrm{g}$ are larger than those of $\mathrm{CoPtB}(\mathrm{O}) / \mathrm{g}$ in all $\mathrm{PO}_{2}$ range. As saturation magnetic induction $4 \pi \mathrm{Ms}$ of $\mathrm{CoPtB}(\mathrm{O})$ film is about $12 \mathrm{kG}$ [1][2], it satisfied the equation of $\mathrm{Hk}>4 \pi \mathrm{Ms}$ in very narrow $\mathrm{PO}_{2}$ range for $\mathrm{CoPtB}(\mathrm{O}) / \mathrm{g}$. This film with large $\mathrm{Hk}$ is identical with the film having the strongest X-ray peak intensity as well as small $\Delta \theta_{50}$. This $\mathrm{PO} 2$ range around $0.035 \mathrm{~Pa}$ is most suitable oxygen partial pressure to achieve high perpendicular anisotropy in $\mathrm{CoPtB}(\mathrm{O}) / \mathrm{g}$. From these results, it would say that the perpendicular anisotropy is closely related to crystallinity of $\mathrm{CoPtB}(\mathrm{O})$ layer.

In Fig.4, $\mathrm{CoPtB}(\mathrm{O}) / \mathrm{Pt} / \mathrm{g}$ satisfies the equation of $\mathrm{Hk}>4 \pi \mathrm{Ms}$ wider $\mathrm{PO} 2$ range compared to $\mathrm{CoPtB}(\mathrm{O}) / \mathrm{g}$. The role of $\mathrm{Pt}$ underlayer is to improve the crystallinity of magnetic layer. With the result that the perpendicular anisotropic films are obtained in wider $\mathrm{PO}_{2}$ range. It should be mentioned that the ds of the films with large perpendicular anisotropy are shrunk by the oxygen incorporation. But it is difficult to tell how these small $\mathrm{d}$ have relation

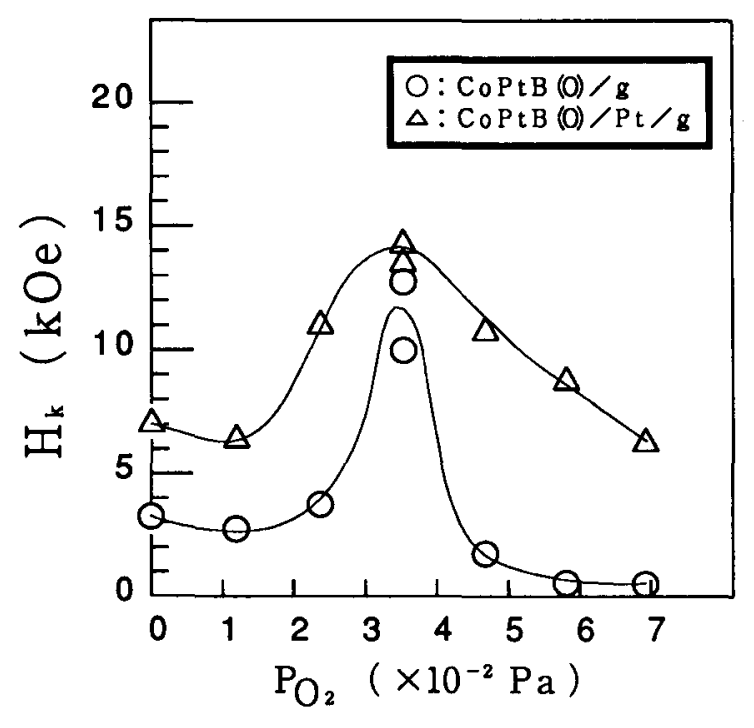

Fig.4 Dependence of $\mathrm{Hk}$ on $\mathrm{PO}$.

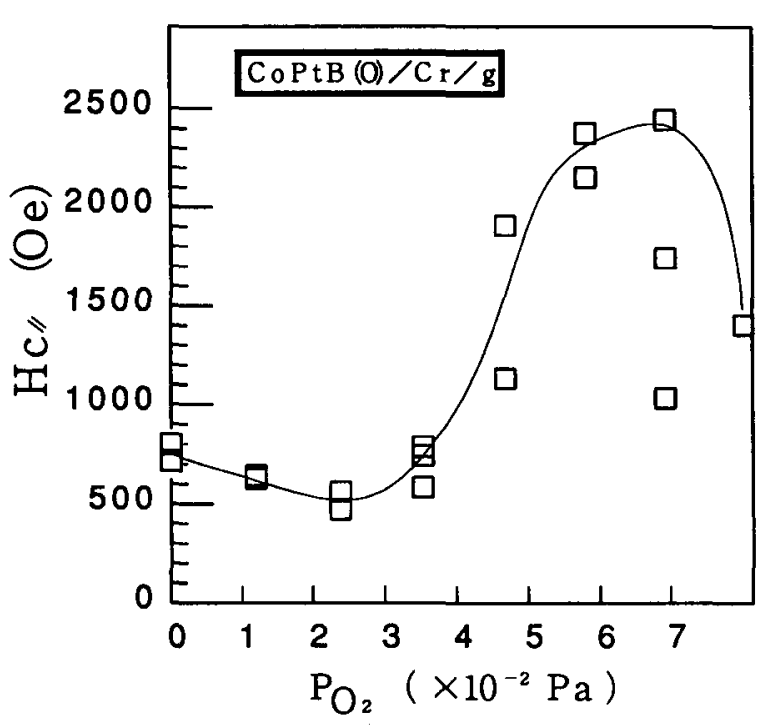

Fig.5 Dependence of in-plane coercivity $\mathrm{Hc} / /$ of $\mathrm{CoPtB}(\mathrm{O}) / \mathrm{Cr} / \mathrm{g}$ on $\mathrm{PO} 2$. 
to the perpendicular anisotropy.

In $\mathrm{CoPtB}(\mathrm{O}) / \mathrm{Cr} / \mathrm{g}$, these films no more retain perpendicular anisotropy but have inplane magnetization. From X-ray diffraction pattern of Fig.1 and X-ray peak intensity of Fig.3, the films of type $\mathrm{CoPtB}(\mathrm{O}) / \mathrm{Cr} / \mathrm{g}$ show small intensity compared to those of the other two type. The difference of magnetic properties may due to the poor crystallinity of $\mathrm{CoPtB}(\mathrm{O})$ layer. Fig.5 shows the dependence of in-plane coercivity $\mathrm{Hc} / /$ on $\mathrm{PO}_{2}$ for the films of $\mathrm{CoPtB}(\mathrm{O}) /$ $\mathrm{Cr} / \mathrm{g}$. Large $\mathrm{Hc} / /$ of about $2500 \mathrm{Oe}$ were obtained from 0.04 to $0.07 \mathrm{~Pa}$ of $\mathrm{PO}$. As these high $\mathrm{He} /$ $\mathrm{PO}_{2}$ region is different from $\mathrm{PO} 2$ range of perpendicular anisotropy region shown in Fig.4, the mechanism of high $\mathrm{Hc} /$ may be independent to perpendicular anisotropy that is realized on $\mathrm{CoPtB}(\mathrm{O}) / \mathrm{g}$ and $\mathrm{CoPtB}(\mathrm{O}) / \mathrm{Pt} / \mathrm{g}$.

\section{Films on continuous substrate}

Fig.6 shows the scheme of sputtering roll coater. Mask and slit limited the incident angle of sputtered particle as only vertical component available (A) and allowed oblique component with vertical one ( $B$ and $C$ ). Arrows with

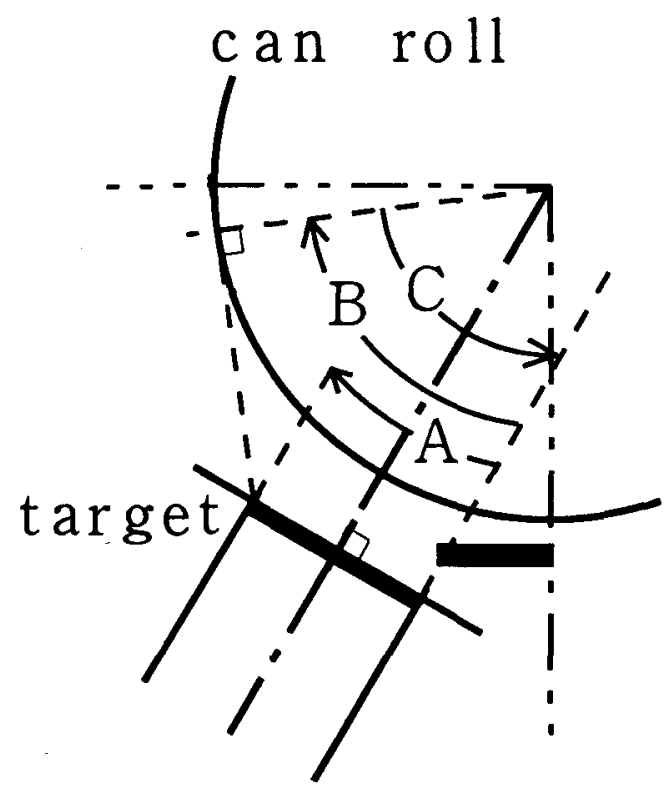

Fig.6 Scheme of sputtering roll coater.

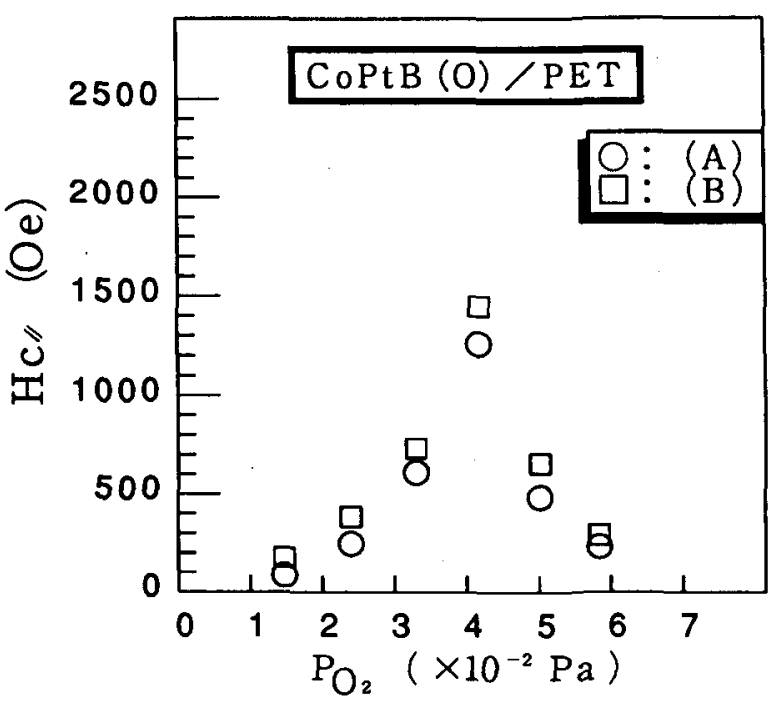

(a) $\mathrm{CoPtB}(\mathrm{O}) / \mathrm{PET}$

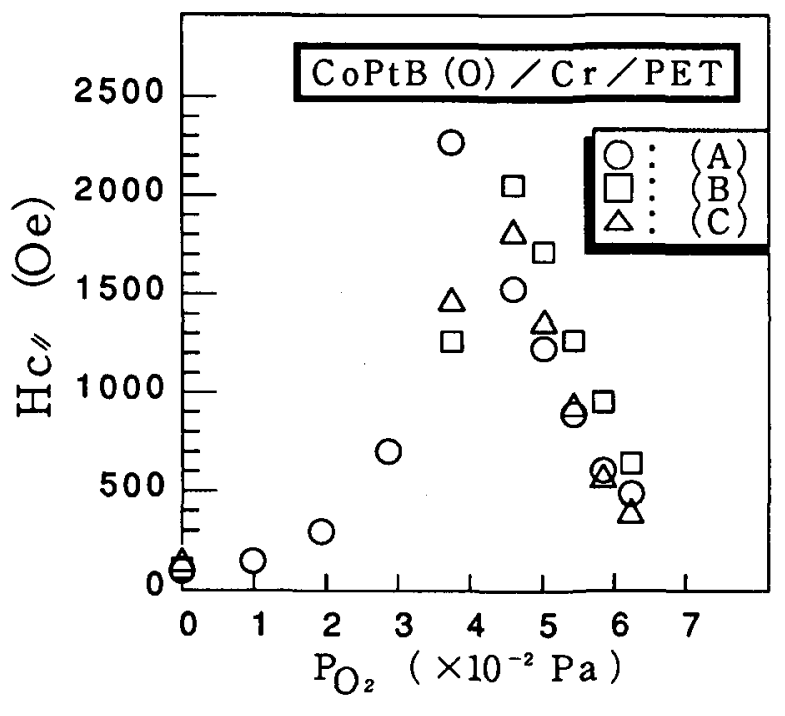

(b) $\mathrm{CoPtB}(\mathrm{O}) / \mathrm{Cr} / \mathrm{PET}$

Fig.7 Dependence of $\mathrm{Hc} / /$ of $(\mathrm{a}) ; \mathrm{CoPtB}(\mathrm{O}) /$ $\mathrm{PET}$ and $(\mathrm{b}) ; \mathrm{CoPtB}(\mathrm{O}) / \mathrm{Cr} / \mathrm{PET}$ on $\mathrm{PO} 2 . \mathrm{A}, \mathrm{B}, \mathrm{C}$ are figured in Fig.6. 


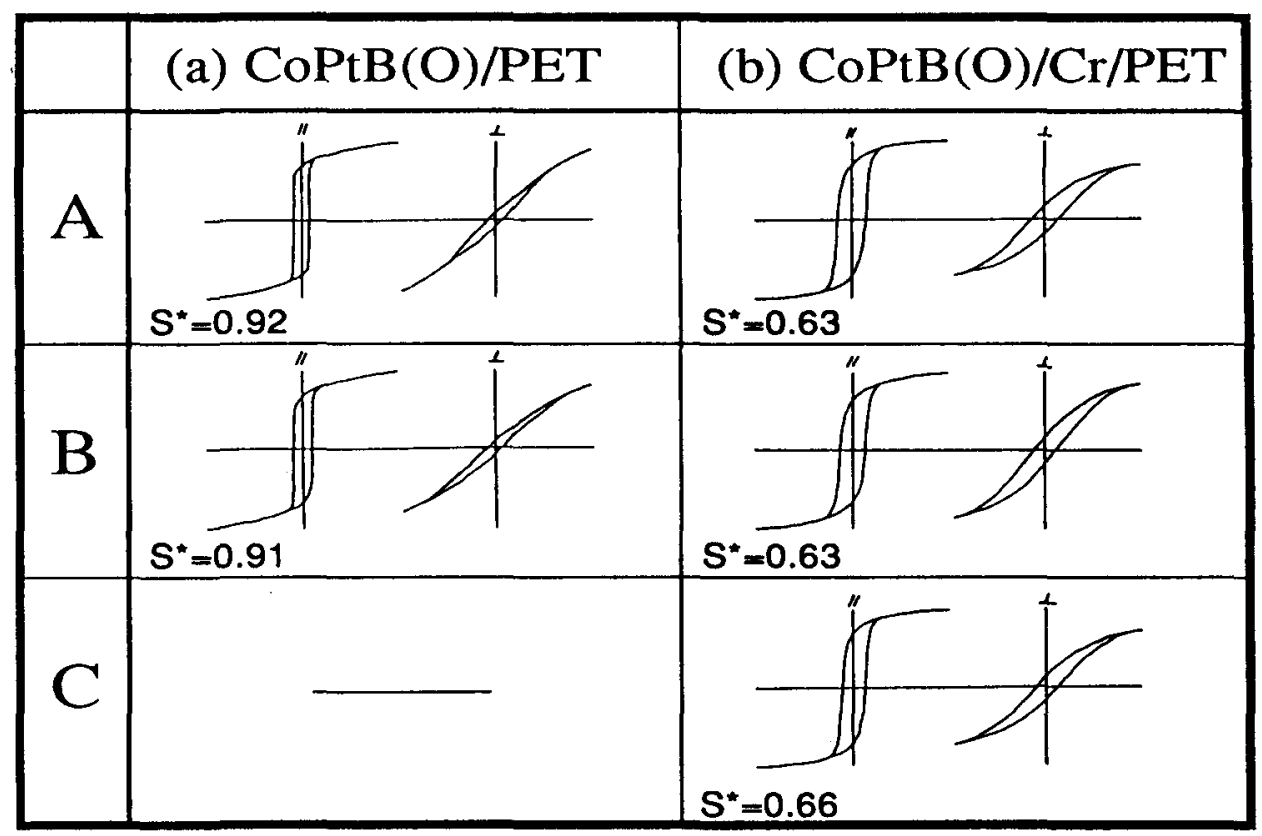

Fig.8

Hysteresis loops of $\mathrm{CoPtB}(\mathrm{O}) / \mathrm{PET} ;(\mathrm{a})$ and $\mathrm{CoPtB}(\mathrm{O}) / \mathrm{Cr} / \mathrm{PET}$;(b). $\mathrm{A}, \mathrm{B}, \mathrm{C}$ are incident angle of sputtered particles in Fig.6.

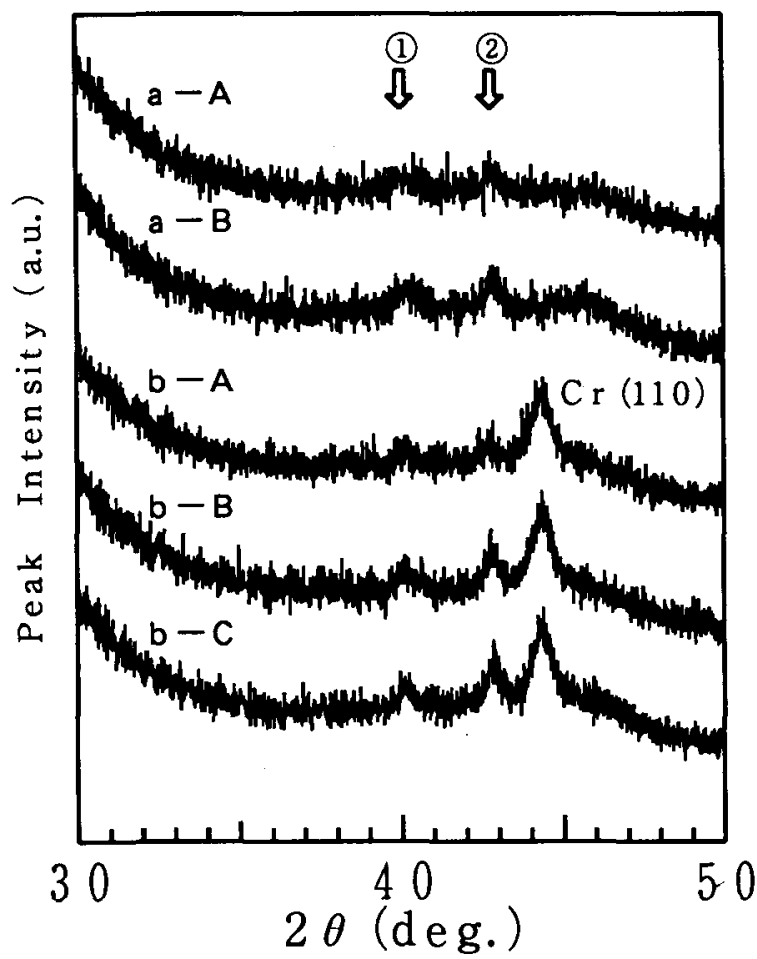

Fig.9 The X-ray diffraction patterns of $\mathrm{CoPtB}(\mathrm{O}) / \mathrm{PET}$;(a) and $\mathrm{CoPtB}(\mathrm{O}) / \mathrm{Cr} /$ PET;(b). A,B,C are incident angle of sputtered particles in Fig.6.

A,B,C also represent the substrate moving direction. The incident angle of range $B$ changed from near vertical to oblique and that of range $\mathrm{C}$ changed from oblique to vertical. The $\mathrm{Cr}$ underlayer was sputtered in the range $A$.

Fig.7 shows the dependence of in-plane coercivity $\mathrm{Hc} / /$ of (a); $\mathrm{CoPtB}(\mathrm{O}) / \mathrm{PET}$ and (b); $\mathrm{CoPtB}(\mathrm{O}) / \mathrm{Cr} / \mathrm{PET}$ on $\mathrm{PO} 2$. All of these films have in-plane magnetization. The maximum $\mathrm{Hc} / /$ of $\mathrm{CoPtB}(\mathrm{O}) / \mathrm{PET}$ is about $1500 \mathrm{Oe}$ at $\mathrm{PO} 2$ of $0.04 \mathrm{~Pa}$ and then decreases with the $\mathrm{PO}_{2}$ increase. This behavior is different from the magnetic properties of $\operatorname{CoPtB}(\mathrm{O})$ layer on the stationary glass slide substrate $(\mathrm{CoPtB}(\mathrm{O}) / \mathrm{g})$.

The $\mathrm{Hc} /$ of $\mathrm{CoPtB}(\mathrm{O}) / \mathrm{Cr} / \mathrm{PET}$ (Fig.7 (b)) is higher in all $\mathrm{PO} 2$ range compared to that of $\mathrm{CoPtB}(\mathrm{O}) / \mathrm{PET}$. The change of $\mathrm{Hc} / /$ is also different from that of $\mathrm{CoPtB}(\mathrm{O}) / \mathrm{Cr} / \mathrm{g}$. These $\mathrm{Hc} / /$ dependence on $\mathrm{PO} 2$ of $\mathrm{CoPtB}(\mathrm{O}) / \mathrm{Cr} / \mathrm{PET}$ is similar to that of $\mathrm{CoPtB}(\mathrm{O}) / \mathrm{PET}$.

Hysteresis loops of these specimens are shown in Fig.8. It can be seen that the coercive squareness $\mathrm{S}^{*}$ decreases by the Cr-underlayer. The differences of the incident angle and the substrate are not clearly recognized from Fig.8. The X-ray diffraction patterns of these specimens are shown in Fig.9. Two peaks from $\operatorname{CoPtB}(0)$ layer were $h c p(100)$ and main peak 
correspond the $(1$ and (2in the figure. All types of these films had bad crystallinity that may result in having in-plane magnetization.

\section{CONCLUSION}

The $\mathrm{Pt}$ and $\mathrm{Cr}$ underlayer effects on magnetic properties and film structure of $\mathrm{CoPtB}(\mathrm{O})$ alloy films are investigated using the stationary glass slide substrate and the continuous PET substrate. The summery is as follows.

1.The perpendicular magnetic properties are closely related to crystallinity of $\mathrm{CoPtB}(\mathrm{O})$ layer.

2.The $\mathrm{Pt}$ underlayer improves crystallinity of $\mathrm{CoPtB}(\mathrm{O})$ and realizes excellent perpendicular anisotropy.

3.The $\mathrm{Cr}$ underlayer changes the magnetic properties of $\mathrm{CoPtB}(\mathrm{O})$ to in-plane magnetization and has maximum $\mathrm{Hc} / /$ of $2500 \mathrm{Oe}$.

4.The $\mathrm{CoPtB}(\mathrm{O})$ alloy films without underlayer on the PET substrate show the in-plane characteristics because of bad crystallinity.

\section{REFERENCES}

[1]K.Hayashi, M.Hayakawa, H.Ohmori, A.Okabe, K.Aso, J.Appl.Phys., "CoPtB(O) alloy films as new perpendicular recording media" 67,pp.5175-5177, (1990).

[2]K. Hayashi, Y.Iwasaki, A.Okabe, T.Yamamoto, M.Hayakawa, K.Aso, "Magnetic properties and microstructure of $\mathrm{Co}-\mathrm{Pt}-\mathrm{B}-\mathrm{O}$ alloy films" Paper presented at M.R.S. spring meeting, (1991). 